\title{
Assessment of different management options used in morbidly adherent placenta
}

\section{and pregnancy outcomes}

\section{Waleed Tawfik}

Department of Obstetrics and Gynecology, Faculty of Medicine, Benha University, Benha, Egypt.

Corresponding author: Waleed Tawfik, Lecturer of Obstetrics and Gynecology, Faculty of Medicine, Benha University, Benha, Egypt. Received Date: March 29, 2020; Accepted Date: April 04, 2020; Published Date: April $10,2020$.

Citation: Waleed Tawfik(2020) Assessment of different management options used in morbidly adherent placenta and pregnancy outcomes. J Women Health Care and Issues, 3(2): Doi: 10.31579/ 2642-9756/026

Copyright: (c) 2020.Waleed Tawfik. This is an open-access article distributed under the terms of the Creative Commons Attribution License, which permits unrestricted use, distribution, and reproduction in any medium, provided the original author and source are credited.

\section{Abstract:}

The aim of this work is evaluation of different management options for patients with morbidly adherent placenta and its effect on pregnancy outcomes to find the best method of management to decrease morbidity and mortality. In this prospective study, there were 42 patients diagnosed as having morbidly adherent placenta previa and hospitalized between January 2019 to February 2020.

Different management options performed to patients with morbidly adherent placenta previa were recorded, blood loss was estimated for each patient, operative procedures, maternal and fetal outcome was recorded.

The results showed the following: Different methods were tried to preserve the uterus including bilateral uterine artery ligation in $13(59 \%)$ cases, bilateral ovarian artery ligation in $3(13.6 \%)$ cases, bilateral internal iliac artery ligation in $3(13.6 \%)$ cases, intrauterine tamponade in $4(18.1 \%)$ cases and hemostatic sutures in placental bed in $11(50 \%)$ cases, while B-lynch suture was not done, while procedures which were performed to control pelvic hemorrhage after hysterectomy included internal iliac artery ligation in $8(27.5 \%)$ cases, pelvic packing in $5(17.2 \%)$ cases and internal iliac balloon inflation to control hemorrhage in $1(3.4 \%)$ case.

The postoperative complications were DIC occurred in 2 patients (4.8\%), ICU admission occurred in 5 cases (11.9\%), two cases required reoperations, one patient $(2.4 \%)$ had wound infection, Postpartum collapse occurred in 2 case (4.8\%). Pulmonary embolism occurred in 1 case (2.4\%), Median duration of hospital stay was 4 days (range: $2-25$ ).

Keyword: morbidly adherent placenta; pregnancy; hemostatic sutures

\section{Introduction:}

The greatest challenge in modern obstetrics remains the morbidly adherent placenta (MAP). At the time of placental separation, the maternal risk tends to result in extreme hemorrhage, disseminated intravascular coagulation (DIC), significant need for blood transfusion, intensive care, hysterectomy and sometimes maternal death $(\mathbf{1 , 2})$.

A multidisciplinary approach is important in treating these patients to reduce MAP-associated morbidity and mortality. The anticipation and management of major hemorrhage, including the availability of packed cells, platelets, fresh frozen plasma, cryoprecipitate and activated factor VII, should be given special consideration. The technology of interventional radiology (3).

Balloon catheter Occlusion of the pelvic arteries or Selective Arterial Embolization reduces blood flow to the uterus and allows surgery to be conducted in simpler and more controlled conditions. Until peripartum hysterectomy, bilateral internal iliac artery ligation is performed in an effort to reduce the surgical blood loss. This is particularly relevant in circumstances where interviews take place

(4).

Few other surgical approaches have been identified, including a hysterectomy, to achieve hemostasis in MAP cases. You may "excision the placental spot" If the placental attachment region is focal and the majority of the placenta is removed, then a "wedge resection" of the region can be carried out $(\mathbf{5 , 6})$

\section{Aim of the Work:}

The goal of this research is to examine various management methods for patients with morbidly adherent placenta and their impact on pregnancy outcomes in order to find the best management approach for decreasing .MAP-related morbidity and mortality

\section{Patients and Methods:}

The present study is a prospective study for pregnant women who were diagnosed as morbidly adherent placenta and hospitalized between January 2019 to February 2020 at the Obstetrics and Gynecology Department, Benha University. Egypt

\section{Inclusion criteria:}

All cases of placenta previa in the third trimester admitted to Zagazig University Hospitals and diagnosed antenatally as morbidly adherent placenta.

\section{Exclusion criteria:}

- Any medical disorder with pregnancy as anemia, hypertension, diabetes, cardiac lesion, liver diseases or kidney diseases.

\section{Sample size:}


The total number of morbidly adherent placenta previa cases admitted to Hospitals per month about 7 cases, so all admitted cases during the period of the study were included equal 42 cases.

Each woman was subjected to the following:

Examination:

A. General examination:

B. Abdominal examination:

\section{Laboratory investigations:}

- A blood sample was withdrawn to check for complete blood count, coagulation profile, liver function tests, renal function tests and random blood sugar.

- A urine sample was taken to check for proteinuria, hematuria and presence of urinary tract infection.

- Blood group, cross matching for blood and plasma before operation

\section{Ultrasound:}

Ultrasound was performed for each patient to confirm viability, gestational age, fetal biometry, fetal presentation, amount of liquor and detailed assessment of placental site, degree of adherence by 2D ultrasound and Doppler

\section{Sonographic features of morbidly adherent placenta by 2D ultrasound:}

1) Retroplacental sonolucent zone deficiency;

2) The lacunae vascular.

3) Thinning myometrials.

4) Bladder line breakage.

5) Exophytic masses present.

\section{Characteristic findings on color Doppler ultrasound include:}

(1) A diffuse lacunar flow pattern with high-velocity pulsatile venous type flow (peak systolic velocity more than $15 \mathrm{~cm} / \mathrm{s}$ ) spread throughout the placenta, myometrium and cervix.

(2) A central lacunar flow pattern with turbulent flow distributed regionally or focally in the parenchyma.

(3) Bladder-uterine serosal interphase hyper vascularity.

(4) Markedly dilated vessels over the peripheral sub placental zone.

(5) An absence of sub placental vascular signals in the areas lacking the peripheral sub placental hypo echoic zone.

(6) Abnormal vascular channels linking the placenta to the bladder.

\section{Counselling:}

- Counseling for the severity of the case.

- Counseling about different management options up to hysterectomy.

- Counseling about the gestational age of termination and possibility of incubator admission.

- Counselling about the desire for future fertility.

\section{Consenting:}

An informed written consent about different management options that may reach to hysterectomy was taken from all patients and their husbands and about the need to blood and blood products during the operation and risk of mortality.

\section{Surgical techniques:}

- $\quad$ All cases with MAP were operated by a senior obstetrician with attendance of a senior anesthesiologist.

- General anesthesia was given to all patients.

- Prophylactic antibiotic was given before skin incision.

- Skin incision: midline or pfannenstiel incision.

- Uterine incision: high transverse incision or vertical upper segment incision.

- Delivery of the baby.

- Hysterectomy without attempt placental removal or trial placental removal followed by conservatives' procedures was left to the experience of the senior obstetrician operating the patient.

- $\quad$ Bilateral internal iliac ballon was inserted before operation and inflated after delivery of the baby to decrease blood loss during surgery in one case.

- If bladder or ureteric injury was suspected urological consultation was done.

\section{Postoperative care:}

- Complete blood count and packed RBCs transfusion if the patient was anemic.

- Early mobilization, good hydration and prophylactic anticoagulant if needed to prevent DVT.

- After discharge the patients returned to outpatient clinic to remove stitches and their wounds were examined for infection.

\section{Estimation of blood loss:}

Real blood loss (ABL) was estimated from a gross formula modification (7) Actual blood loss= BV $\{\operatorname{Hct}(\mathrm{i})-\operatorname{Hct}(\mathrm{f})\} / \operatorname{Hct}(\mathrm{m}) \mathrm{BV}$ : volume of blood. Blood volume is determined by using the following formula, dependent on body weight. Blood volume $=$ Body weight (in $\mathrm{Kg}$ ) at 70 $\operatorname{Hct}(\mathrm{i})$ : initial hematocrit $\operatorname{Hct}(\mathrm{f})$ : final hematocrit $\operatorname{Hct}(\mathrm{m})$

\section{Neonatal care:}

- All neonates were examined by pediatrician with detection of APGAR score, gender and birth weight.

\section{Statistical analysis:}

Data collected, recorded, entered and analyzed using Microsoft Excel software throughout history, basic clinical evaluation, laboratory investigations and outcome measures. Data was then imported into the Social Sciences version 16.0 Statistical Package. (V16 SPSS). Depending on the type of qualitative data expressed as number and percentage

\section{Results:}

The present retrospective research was performed over the period from December 2018 to May 2019 on cases of morbidly-adherent placenta prioria. This research contained a total of 42 cases of morbidly-adherent placenta prioria.

as shown in table (1). Among the included 42 women with morbidlyadherent placenta previa, $20(47.61 \%)$ cases presented with antepartum hemorrhage (APH), Among the included 42 women, morbid placental adherence by preoperative U/S was in the form of 'focal accreta' in 13 (31\%) women, 'accreta' in $14(33.4 \%)$ women, 'increta' in $10(23.8 \%)$ women and 'percreta' in $5(11.9 \%)$ women, as shown in table (2)

Among the included 42 women with morbidly-adherent placenta previa, $14(33.3 \%)$ cases had urgent surgery due to antepartum hemorrhage or uterine contraction, while $28(66.7 \%)$ had elective surgery, Trial of placental removal plus application of conservative measures was done in $22(52.4 \%)$ women that succeeded in $13(31 \%)$ women (CS only) and 
failed in 9 (21.4\%) women (hysterectomy), Hysterectomy was done in $20(47.6 \%)$ women from the start without trial of placental removal, Among the included 42 women, midline incision was done in 13 (31\%) cases and pfannenstiel incision was done in $29(69 \%)$ women as shown in table (3)

Intraoperatively, removal of the placenta was tried in $22(52.4 \%)$ cases, different methods were tried to preserve the uterus including bilateral uterine artery ligation in $13(59 \%)$ cases, bilateral ovarian artery ligation in $3(13.6 \%)$ cases, bilateral internal iliac artery ligation in $3(13.6 \%)$ cases, intrauterine tamponade (uterine pack or Foley catheter) was placed in $4(18.1 \%)$ cases and hemostatic sutures in placental bed in 11(50\%) cases, while B-lynch suture was not done, Intraoperatively, procedures which were performed to control pelvic hemorrhage after hysterectomy included internal iliac artery ligation in $8(27.5 \%)$ cases, pelvic packing in $5(17.2 \%)$ cases and internal iliac balloon inflation to control hemorrhage in $1(3.4 \%)$ case, Bladder injury occurred in $7(16.7 \%)$ cases and ureteric injury occurred in only $1(2.4 \%)$ case with ureteric stent insertion, while vascular and intestinal injury did not occur as shown in table (4)

The estimated median blood loss intraoperatively was $2 \mathrm{~L}$ (range: 1-8 L). Both cases need transfusion into the blood. The median was four units (range: 1-17). FFP transfusion overall concentrations were 39/42 (92.85 per cent). The median was 2 units (range: $1-8$ units). Only 2 (4.76 per cent) women received platelet transfusion and only 3 (7.14 per cent) women were transfused with cryoprecipitate. Only 1 (2.4\%) woman needed recombinant activated factor vii due to DIC, Of the included 42 women, $2(4.8 \%)$ cases developed DIC, $5(11.9 \%)$ cases were admitted to ICU postoperatively, 1 (2.4\%) case developed wound infection, 1 (2.4\%) case developed pulmonary embolism , 2 (4.8\%) women developed postpartum collapse and $2(4.8 \%)$ cases were re-operated again (for evacuation of hematoma and the second case for removal of abdominal packs which was left to control pelvic hemorrhage after hysterectomy), only $1(2.4 \%)$ case died during the study period from internal hemorrhage, According to table (5), the median hospital stay after delivery was 4 days (range: $2-25$ days).

Of the 42 neonates who were included, $24(57.1 \%)$ were males, while 18 $(42.8 \%)$ were females. As shown in table (6), the median birth weight was $3.1 \mathrm{Kg}$ (range: $1.6-3.8 \mathrm{Kg}$ ) and the median Apgar score was 7 (range: $1-$ 9).

\begin{tabular}{|l|c|}
\hline Age (Years) & $21-43$ \\
Range & $32.21 \pm 5.28$ \\
Mean \pm SD & \\
\hline Gestational Age at delivery (Weeks) & $33-39$ \\
Range & $36.61 \pm 1.60$ \\
Mean \pm SD & $1-5$ \\
\hline Parity & 3 \\
Range & $1(2.38 \%)$ \\
Median & $6(14.28 \%)$ \\
\hline No. of Previous CS & $13(30.95 \%)$ \\
$\mathbf{0}$ & $14(33.33 \%)$ \\
$\mathbf{1}$ & $7(16.66 \%)$ \\
$\mathbf{2}$ & $1(2.38 \%)$ \\
$\mathbf{3}$ & \\
$\mathbf{4}$ & $18(42.9 \%)$ \\
$\mathbf{5}$ & $1(2.38 \%)$ \\
\hline No. of previous D\&C & 1 \\
\hline
\end{tabular}

\begin{tabular}{|l|c|}
\hline Degree of Morbid Adherence & \\
Focal accreta & $13(31 \%)$ \\
Accreta & $14(33.4 \%)$ \\
Increta & $10(23.8 \%)$ \\
Percreta & $5(11.9 \%)$ \\
\hline APH & \\
Yes & $20(47.61 \%)$ \\
No & $22(52.38 \%)$ \\
\hline
\end{tabular}

Table (2): APH as the Presenting Complaint and Degree of Morbid Placental Adherence by preoperative U/S evaluation:

\begin{tabular}{|l|c|}
\hline Elective surgery & $28(66.7 \%)$ \\
Urgent surgery & $14(33.3 \%)$ \\
\hline CS only & $13(31 \%)$ \\
Caesarean Hysterectomy & $29(69 \%)$ \\
\hline Midline & $13(31 \%)$ \\
Pfannenstiel & $29(69 \%)$ \\
\hline
\end{tabular}

Table (3): Type of surgery and skin incision

\begin{tabular}{|l|c|}
\hline Intraoperative procedures & $\begin{array}{c}\text { Total number of } \\
\text { cases=22 }\end{array}$ \\
\hline Bilateral uterine artery ligation & $13(59 \%)$ \\
\hline Bilateral ovarian artery ligation & $3(13.6 \%)$ \\
\hline Uterine tamponade & $4(18.1 \%)$ \\
\hline Internal iliac artery ligation & $3(13.6 \%)$ \\
\hline Hemostatic sutures in placental bed & $11(50 \%)$ \\
\hline B-lynch & 0 \\
\hline Intraoperative procedures & Total number of \\
& cases=29 \\
\hline Internal iliac artery ligation & $8(27.5 \%)$ \\
\hline Pelvic packing & $5(17.2 \%)$ \\
\hline Internal iliac balloon & $1(3.4 \%)$ \\
\hline Intraoperative complications & Total number of \\
& cases=42 \\
\hline Bladder injury & $7(16.7 \%)$ \\
\hline Ureteric injury & $1(2.4 \%)$ \\
\hline Intestinal injury & 0 \\
\hline Vascular injury & 0 \\
\hline
\end{tabular}

Table (4): Intraoperative procedures performed to conserve the uterus after trial of placental removal:

\begin{tabular}{|l|c|}
\hline Estimated intraoperative blood loss & $\begin{array}{c}\text { Total number of cases= } \\
\mathbf{4 2}\end{array}$ \\
\hline $\begin{array}{l}\text { Estimated Blood Loss (L) } \\
\text { Range } \\
\text { Median }\end{array}$ & $1-8$ \\
& 2 \\
\hline $\begin{array}{l}\text { Blood Transfusion (RBCs units) } \\
\text { Range } \\
\text { Median }\end{array}$ & $1-17$ \\
\hline FFP Transfusion & 4 \\
\hline
\end{tabular}

Table (1): Patient clinical characteristics and Risk factors 


\begin{tabular}{|l|c|}
\hline $\begin{array}{l}\text { FFP Transfusion(units) } \\
\text { Range } \\
\text { Median }\end{array}$ & $1-8$ \\
\hline Platelet Transfusion & $2(4.76 \%)$ \\
\hline Cryoprecipitate Transfusion & $3(7.14 \%)$ \\
\hline Recombinant activated factor vii & $1(2.4 \%)$ \\
\hline Postoperative complications & $\begin{array}{c}\text { Total number of } \\
\text { cases=42 }\end{array}$ \\
\hline DIC & $2(4.8 \%)$ \\
\hline ICU admission & $5(11.9 \%)$ \\
\hline Reoperation & $2(4.8 \%)$ \\
\hline Wound infection & $1(2.4 \%)$ \\
\hline Postpartum collapse & $2(4.8 \%)$ \\
\hline Pulmonary embolism & $1(2.4 \%)$ \\
\hline Mortality & $1(2.4 \%)$ \\
\hline $\begin{array}{l}\text { Duration of hospital stay (days) } \\
\text { Median }\end{array}$ & $2-25$ \\
\hline
\end{tabular}

Table (5): Estimated intraoperative blood loss, Postoperative complications and blood transfusion in included women with morbidly adherent placenta previa

\begin{tabular}{|l|c|}
\hline & Total number of cases $\mathbf{4 2}$ \\
\hline Neonatal Gender & $24(57.1 \%)$ \\
Male & $18(42.8 \%)$ \\
Female & $1.6-3.8$ \\
Birth Weight $\mathbf{K g})$ & 3.1 \\
Range & $1-9$ \\
Median & 7 \\
\hline Apgar Score & \\
Range & \\
Median & \\
\hline
\end{tabular}

Table (6): Neonatal outcome in included women with morbidly adherent placenta previa

\section{Discussion}

.Although, until recently, Morbidly attached placenta has been considered a relatively rare occurrence, its annual incidence seems to be rising. In 1994, the incidence of morbidly adherent placenta over the previous 10 years was estimated to be 1 in 2510 cases, while a 2002 study recorded an incidence of 1 in 533 cases over the preceding 20 years and an incidence of 1 in 210 cases in $2006 \mathbf{( 8 , 9 ) . ~}$

In the current study 42 cases diagnosed prenatal as morbidly adherent placenta, In 20(47.6\%) women hysterectomy was done without trial of placenta removal, In 22(52.4\%) women trial of placental removal was done preceded by uterine massage and uterotonics and followed by conservatives procedures to control bleeding from the placental bed. Due to absence of management protocol for morbidly adherent placenta in our emergency hospital, so hysterectomy without attempt placental removal or trial placental removal followed by conservatives procedures was left to the experience of the senior obstetrician operating the patient.

Generally speaking, trial placental removal was performed in many cases mainly due to low parity of many patients and their desire for future fertility and prenatal U/S (greyscale and Doppler) not has $100 \%$ accuracy for diagnosis morbidly adherent placenta. Intraoperative findings of percreta and high vascularity of the lower uterine segment are the main two factors that forced the obstetrician to perform hysterectomy from the start without attempt of placental removal.

In a study by Deeba F.N et al., (2016) they reported the following incidences of abnormal placentation by U/S: placenta accreta in 16 $(69.6 \%)$ women, placenta increta in $3(13 \%)$ women and placenta percreta in $4(17.4 \%)$ women. In the present study the incidences of abnormal placentation: placenta accreta $64.28 \%$ (24 cases); placenta increta $23.8 \%$ (10 cases) and placenta percreta $11.9 \%$ (5 cases).(10,11)

In the current study $20(47.61 \%)$ cases presented with antepartum hemorrhage (APH), $14(33.3 \%)$ women had urgent surgery due to antepartum hemorrhage or uterine contraction

In our study population there was no significant difference (P: 0.64) between elective and urgent surgery as regard blood loss, also Biler A, et al., 2016 reported in their study that no observed significant differences between patients underwent elective and emergency surgery as regard blood loss .(12)

In the current study midline incision was done in $31 \%$ cases and pfannenstiel incision was done in $69 \%$ women

Intraoperatively trial placental removal plus conservative procedures were performed in $22(52.4 \%$ ) cases that succeeded in $13(59 \%)$ women who had CS only, failed in $9(40.9 \%)$ women who had hysterectomy, while hysterectomy was done in 20(47.6\%) women with placenta lift in situ without attempts of placental removal, While Biler A, et al. 2016 (12) in their study reported that $11(22 \%)$ women had hysterectomy without removal of the placenta, while $38(78 \%)$ Women have been guided conservatively. After delivery in all these cases the placenta was removed. Uterine compression sutures, bilateral uterine artery ligation, bilateral hypogastric artery ligation were used according to the degree of bleeding, and two or more techniques were performed if needed. Because of hemodynamic instability, $8(21 \%)$ patients were hysterectomized during the cesarean section, while in a study by Deeba F.N et al., (2016) they reported that majority of patients $17(74 \%)$ underwent caesarean hysterectomy without trial removal of the placenta, Placental removal was performed in $6(26 \%)$ patients all having focal adherence of placenta (11). Uterine preserving procedures were performed and succeeded in $13(31 \%)$ cases, bilateral uterine artery ligation in $13(59 \%)$ cases, bilateral ovarian artery ligation in $3(13.6 \%)$ cases, bilateral internal iliac artery ligation in $3(13.6 \%)$ cases, intrauterine tamponade (uterine pack or Foley catheter) was placed in $4(18.1 \%)$ cases, hemostatic sutures in placental bed in 11(50\%) cases, While Biler A, et al. 2016 in their study reported that bilateral uterine artery ligation was done in $12(31.5 \%)$ cases, bilateral internal iliac artery ligation in $20(52.6 \%)$ cases, compression sutures in $19(50 \%)$ cases. (11)

Intraoperatively, many procedures were performed to control pelvic hemorrhage after hysterectomy, internal iliac artery ligation in $8(27.5 \%)$ cases, pelvic packing in $5(17.2 \%)$ cases and internal iliac balloon was inflated to control hemorrhage in $1(3.4 \%)$ case, in a study by Eller et al., 2009 (13) they reported that $20(36 \%)$ cases need bilateral internal iliac artery ligation, while Fitzpatrick KE et al., 2014 (14) in their study reported that $11(8 \%)$ women had internal iliac balloon was inflated to control hemorrhage, and $16(12 \%)$ women had intra-abdominal packing. 
Recent research has shown that in suspected cases of morbidly adherent placenta, scheduled cesarean hysterectomy substantially decreased the risk of early morbidity (long maternal ICU admission, large volume of blood transfusion, coagulopathy, or early reoperation) compared with cases of unsuspected accreta, where placental removal was sometimes attempted (15)..

In the current study, the overall rate of FFP transfusion was $39 / 42$ $(92.85 \%)$ mean FFP use, 2.71 . Only $2(4.7 \%)$ woman received platelet transfusion, only $3(7.14 \%)$ woman received cryoprecipitate transfusion and only $1(2.4 \%)$ woman need Recombinant activated factor VII. While Fitzpatrick KE et al., 2014 reported that 5 (4\%) women need Recombinant activated factor VII.(14)

In the current study, there was highly significant increase in blood loss, hospital stay and amount of blood transfusion in cases performed hysterectomy after trial placental removal when they compared with patients performed CS only or hysterectomy without trial placental removal, in a study by Fitzpatrick KE et al., 2014 A cohort of 134 women who were diagnosed with placenta accreta, increta or percreta did not attempt to extract either of the placenta, maintain the uterus or hysterectomy, were associated with reduced rates of hemorrhage and reduced need for blood transfusion, but confirmed that there was no substantial difference in hospital stay..(14)

MAP is associated with significant maternal mortality. Studies have shown mortality rate of $7-10 \%$ (leena $W$ et al., 2013). In the current study there was only 1 (2.4\%) case maternal mortality.In our study population, morbidity like DIC , postpartum collapse, pulmonary embolism occurred only in cases that had hysterectomy after attempt placental removal, also mortality occur only in one case had hysterectomy after attempt placental removal due to internal hemorrhage. (17)

James indicated that females favors the sex ratio associated with morbidly adherent placenta (James, 1995) (18). Of the 42 neonates included, 24 (57.1 percent) were males in the present sample while 18 (42.8 percent) were females. Therefore, the conclusion of the present research is contradictory to that of the previous literature.

prospective population-based architecture is a major strength of our research, not depending on regularly coded data to determine cases. There were some drawbacks to the prospective analysis. The sample size was inadequate to distinguish variations in complications with different management approaches, regulation of bleeding differentiated in each case, management decisions were taken at the discretion of the case

\section{Conclusion:}

In conclusion, up till now there is not completely sensitive and specific test for the diagnosis of MAP, when morbidly adherent placenta is diagnosed or suspected antenatally, delivery should be scheduled in a tertiary care center with appropriate expertise and facilities. Generally, the recommended management is cesarean hysterectomy. However, this approach might not be considered the first line of treatment in women who have a strong desire for future fertility. Therefore, surgical management of morbidly adherent placenta may be individualized, available quantity of blood products and multidisciplinary approach may reduce maternal morbidity and mortality in these patients, Good anticipation and timely decision is the key to success in this lifethreatening condition.

\section{Recommendations:}

The recommended management for morbidly adherent placenta is hysterectomy without attempt placental removal especially if there are signs of placental invasion, but in nulliparous women we recommended conservative measures to safe the uterus and no hurry for hysterectomy to give the chance for placental separation.

\section{References:}

1. Usta IM, Hobeika EM, Musa AA. Placenta previa-accreta : risk factors and complications. Am J Obstet Gynecol 2005;193:1045-9.

2. Wong HS, Chung YK, Strand L. Specific sonographic features of placenta accreta tissue interface description on grayscale imaging and evidence of vessels crossing interface disruption sites on doppler ultrasound. Ultrasound Obstet Gynecol 2007; 29:239-41

3. ACOG Practice Bulletin. Anemia in pregnancy. No. 95. American College of Obstetricians and Gynecologists. Obstet Gynecol 2008; 112:201-7.

4. Kidney DD, Nguyen AM, Ahdoot D, Bickmore D, DeutschLS, Majors C. Prophylactic perioperative hypogastric artery balloon occlusion in abnormal placentation. Am J Roentgenol2001; 176(6): 1521-4.

5. Nishijima K, Shukunami K, Arikura S, Kotsuji F. An operative technique for conservative management of placenta accreta.Obstet Gynecol 2005;105:1201-3

6. Chan BCP, Lam HSW, Yuen JHF, Lam TPW, Tso WK, PunTC, Lee CP. Conservative management of placenta praevia with Accreta. Hong Kong Med J 2008; 14(6): 479-84.

7. Ajjammanavar V, Jayashree S, Amrutha B. Blood loss assessment in abdominal hysterectomy: how accurate? Int $J$ Reprod Contracept Obstet Gynecol 2016;5:306-9

8. Stafford I and Belfort M. Placenta accreta, increta, and percreta: a team-based approach starts with prevention. Contemp Ob Gyn 2008; 53 (4): 76-82.

9. Cali G, Giambanco L, PuccioG. Morbidly adherent pla- centa: evaluation of ultrasound diagnostic criteria and differentia- tion of placenta accreta from percreta. Ultrasound Obstet Gynecol 2013;41:406-412.

10. 1Silver RM, Barbour KD. Placenta accreta spectrum: accreta, incre- ta, and percreta. Obstet Gynecol Clin North Am 2015;42:381-402.

11. Deeba F, Khan A, Haque S. Review of cases of morbidly adharent placenta in a tertiary care unit. MC Vol. 22 - No.1 2016 ( 43-47)

12. Biler A, Ekin A, Gezer C. A single center experience on the management of placental invasion abnormalities: JCEI 2016; 7 (1): 14-18

13. Eller AG, Porter TF, Soisson P. Optimal management strategies for placenta accreta. BJOG 2009;116:648-54.

14. Fitzpatrick KE, Sellers S, Spark P. The management and outcomes of placenta accreta, increta, and percreta in the UK: a population-based descriptive study. BJOG 2014;121:62-71.

15. Oyelese Y, Smulian JC. Placenta previa, placenta accreta, and vasa previa. Obstet Gynecol. 2006; 107(4):927-941.

16. Warshak CR, Ramos GA, Eskander R. Effect of predelivery diagnosis in 99 consecutive cases of placenta accreta. Obstet Gynecol 2010; 115:65.

17. leena W, Sangeeta G, Partibha G. Morbidly adherent placenta (MAP) : Lesson learnt .open Journal of Obstet Gynecol 2013 ; $3: 217-222$

18. James WH. Sex ratios of offspring and the causes of placental pathology. Hum Reprod 1995; 10:1403. 